\title{
Pendampingan UMKM dalam Penggunaan Digital Marketing pada Komunitas UMKM di Kabupaten Madiun
}

\author{
Slamet Riyanto', Muh Nur Luthfi Azis², Andi Rahman Putera ${ }^{3}$ \\ 1,2,3 Universitas PGRI Madiun \\ e-mail: 1selamat@unipma.ac.id, 2nur.azis@unipma.ac.id, \\ 3andirahmanputera@unipma.ac.id
}

\begin{abstract}
Abstrak
Kegiatan pengabdian kepada masyarakat yang dilakukan pada tahun 2021 ini memiliki tujuan untuk melakukan pendampingan kegiatan digital marketing pada komunitas UMKM di Kabupaten Madiun, bentuk pendamping dilakukan dalam bentuk pembuatan toko online di marketplace Shopee dan Tokopedia. Pelaksanaan pengabdian kepada masyarakat dilaksanakan pada tanggal 9 - 14 Agustus 2021, dengan materi teknik foto produk, video produk dan pembuatan logo usaha, membuka dan pengaturan toko online di Shopee dan Tokopedia. Pelaksanaan pengabdian kepada masyarakat dengan tema digital marketing dengan peserta sebanyak 16 orang, dimana peserta adalah pelaku usaha yang telah memiliki usaha dengan skala mikro dan menengah. Untuk pelaksanaan kegiatan ini telah berjalan dengan lancar dan kehadiran peserta dalam setiap pertemuan mencapai $90 \%$. Selain itu, peserta juga dapat mempelajari materi secara offline maupun online dari hasil rekaman yang telah dibuat.
\end{abstract}

Kata kunci: UMKM, digital marketing, marketplace

\begin{abstract}
This community service activity carried out in 2021 has the aim of assisting digital marketing activities in the MSME community in Madiun Regency. The abdimas implementation will be held on August 9-14, 2021, with technical material for product photos, product videos $\mathcal{E}$ making business logos, opening and setting online stores at Shopee and Tokopedia. Implementation of community service with the theme of digital marketing with 16 participants, where participants are business actors who already have micro and medium scale businesses. The implementation of this activity has been running smoothly and the attendance of participants in each meeting has reached $90 \%$. In addition, participants can also study the material offline or online from the recordings that have been made.
\end{abstract}

Keywords: MSMEs, digital marketing, marketplace

\section{Pendahuluan}

Program pengabdian kepada masyarakat dengan tema digital marketing merupakan program pelatihan peningkatan kompetensi yang ditujukan kepada pelaku usaha yang ingin atau telah memiliki usaha dalam skala Usaha Mikro, Kecil, dan Menengah (UMKM) (Hapsoro, 2019). Digital marketing adalah salah satu media pemasaran yang 
saat ini sedang banyak diminati oleh masyarakat untuk mendukung berbagai kegiatan yang dilakukan (Gumilang, 2019). Salah satu kekuatan ekonomi yang selama ini menjadi penunjang ekonomi negara Indonesia dan kekuatan ekonomi daerah adalah kehadiran pelaku usaha, mikro, kecil dan menengah (UMKM) (Febriyantoro \& Arisandi, 2018). Kegiatan pengabdian kepada masyarakat ini dapat membekali UMKM menjadi unggul dalam mendukung era revolusi industri 4.0, dimana pengguna internet yang cukup besar terutama penggunaan media sosial harus bisa digunakan oleh UMKM untuk menjangkau pasarnya dengan cara yang benar (Djamaludin et al., 2016).

Program pengabdian kepada masyarakat diharapkan menjadi solusi bagi pelaku usaha untuk memulai usaha dengan risiko yang rendah, dimana pelaku usaha akan dibekali kemampuan untuk membuka toko online di beberapa marketplace yang telah ada. Program ini juga memiliki keunggulan bahwa peserta pelatihan dapat memulai usaha dengan modal yang sangat minim dan mendapatkan keuntungan yang besar, misalnya menjadi dropshipper, reseller maupun supplier di marketplace.

Trend digital marketing menjadi peluang bagi UKM untuk menyambut era industri 4.0 (Irfani et al., 2020). Digital marketing memudahkan promosi penjualan, seperti penggunaan media sosial yang banyak digunakan oleh para pemasar (Oktaviani \& Rustandi, 2018). Digital marketing mampu mempengaruhi keputusan pembelian melalui berbagai media sosial yang digunakan oleh pelaku usaha (Harto et al., 2021). Kegiatan digital entrepreneurship menjadi kegiatan bisnis yang sangat menarik, dimana peserta sangat dapat dengan mudah untuk melakukan praktik bisnis di marketplace yang sudah ada (Gunawan, 2020). Kegiatan digital entrepreneurship ini mampu menjadi pelaku usaha berperilaku kreatif dan inovatif dalam melakukan kegiatan bisnis dengan memanfaatkan teknologi informasi (Nugraha, 2017).

Tujuan dari program pengabdian kepada masyarakat ini adalah: melakukan pendampingan kegiatan digital marketing pada komunitas UMKM di Kabupaten Madiun dan memastikan keberlangsungan usaha dari komunitas UMKM di Kabupaten Madiun. Selain ini kegiatan digital marketing akan meningkaykan penjualan dan laba, perluasan pangsa pasar, pendalaman loyalitas pelanggan, dan peningkatan keunggulan kompetitif (Perwita, 2021).

Manfaat yang diperoleh dari kegiatan ini bagi bagi peserta pelatihan adalah untuk meningkatkan pengetahuan dan keahlian komunitas UMKM dalam digital marketing untuk meningkatkan promosi produk secara modern. Dan meningkatkan kegiatan produksi melalui peningkatan pesanan produk dari pangsa pasar yang lebih luas. Selain itu, hasil kegiatan ini juga memberikan manfaat bagi tim pelaksana, yaitu: memberikan pembelajaran sosial bagi dosen dan mahasiswa untuk menyelesaikan permasalahan-permasalahan riil yang ada di masyarakat. Dosen dan mahasiswa mengimplementasikan keilmuan yang telah dipelajari di kampus (desain grafis, ecommerce, multimedia, pengantar manajemen, kewirausahaan dan mata kuliah lainnya) sehingga memberikan manfaat bagi masyarakat. Dan melakukan hilirisasi hasil riset dan implementasi pengetahuan untuk kemajuan UMKM. 


\section{Metode}

Pelaksanaan pengabdian kepada masyarakat dilakukan secara online melalui media zoom, dimana peserta dan pemateri dalam suatu ruang meeting dan melakukan pembelajaran secara bersama-sama. Dalam kegiatan pelatihan ini menggunakan metode ceramah, praktik dan penugasan. Selain itu, tim pelaksana pengabdian kepada masyarakat juga memanfaatkan media sosial berupa Group Whatshap dalam kegiatan diskusi dan konsulting terkait dengan materi yang diberikan.

Pelaksanaan pengabdian kepada masyarakat dilaksanakan pada tanggal 9 - 14 Agustus 2021, dengan total jam pelaksanaan per sesi sebanyak 3 jam. Kegiatan pelatihan sebanyak tiga kali pertemuan secara online dengan uraian kegiatan sebagai berikut:

Tabel 1 Uraian Kegiatan

\begin{tabular}{|c|l|l|}
\hline Tgl & \multicolumn{1}{|c|}{ Materi } & \multicolumn{1}{|c|}{ Pemateri } \\
\hline $\begin{array}{c}\text { 9 Agustus } \\
2021\end{array}$ & $\begin{array}{l}\text { Teknik Foto Produk, Video Produk } \\
\text { \& Pembuatan logo usaha }\end{array}$ & Slamet Riyanto, ST., MM \\
\hline $\begin{array}{c}11 \text { Agustus } \\
2021\end{array}$ & $\begin{array}{l}\text { Membuka dan pengaturan toko } \\
\text { online di Shopee }\end{array}$ & $\begin{array}{l}\text { Muh Nur Luthfi Azis, S.Kom, } \\
\text { M.Kom }\end{array}$ \\
\hline $\begin{array}{c}\text { 14 Agustus } \\
2021\end{array}$ & $\begin{array}{l}\text { Membuka dan pengaturan toko } \\
\text { online di Tokopedia }\end{array}$ & $\begin{array}{l}\text { Muh Nur Luthfi Azis, S.Kom, } \\
\text { M.Kom }\end{array}$ \\
\hline
\end{tabular}

Untuk menentukan peserta dalam kegiatan pengabdian kepada masyarakat ini, maka tim abdimas mempertimbangkan kepada beberapa hal, diantaranya: 1. Peserta pelatihan memiliki kemampuan dalam mengoperasikan smartphone dan laptop; 2. Peserta pelatihan telah memiliki usaha atau memiliki produk untuk dijual secara online; 3 . Bersedia mengikuti kegiatan pengabdian kepada masyarakat hingga selesai. Dari hasil seleksi diperoleh peserta pelatihan digital marketing sebanyak 16 peserta.

Peserta pelatihan juga mendapatkan e-book pelatihan yang dapat digunakan sebagai panduan dalam praktik pembukaan toko online di marketplace Shopee dan Tokopedia.

\section{Hasil dan Pembahasan}

Kegiatan pengabdian kepada masyarakat ini dilakukan secara daring dengan mitra sasaran pelaku UMKM yang ada di Kabupaten Madiun. Dokumentasi dari kegiatan pengabdian kepada masyarakat ini dapat ditampilkan sebagai berikut:

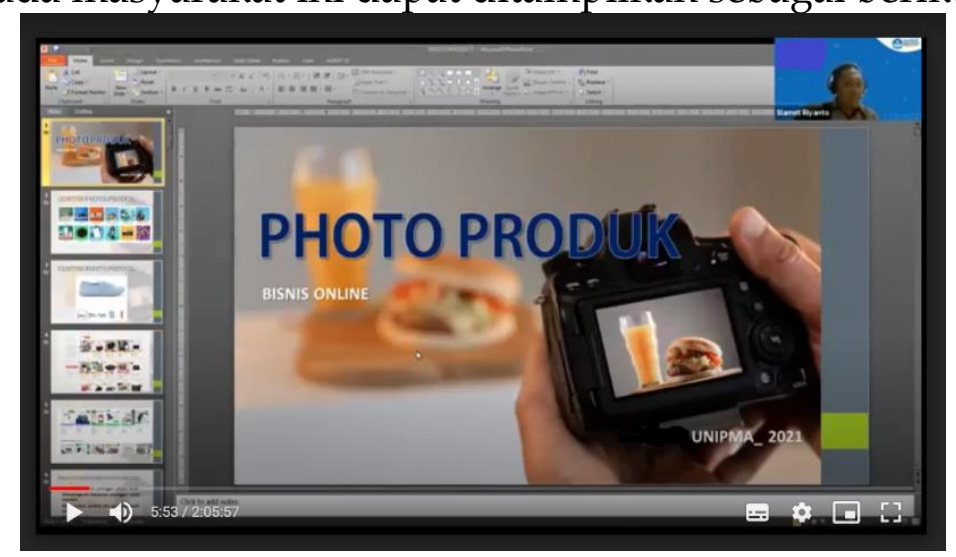

Gambar 1. Penyampaian Materi Teknik Foto Produk 


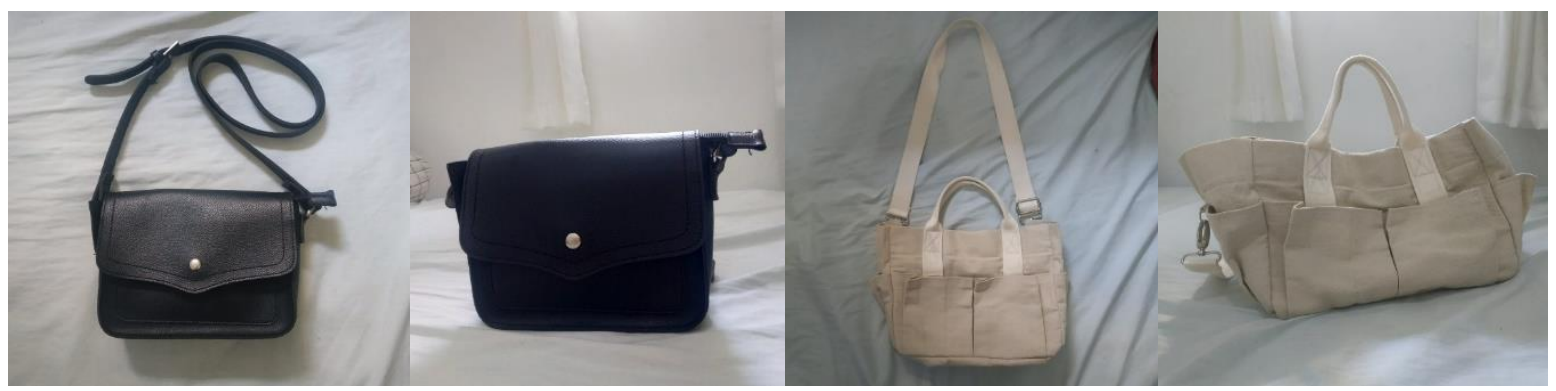

Gambar 2. Hasil Foto Produk Dari Peserta Pelatihan
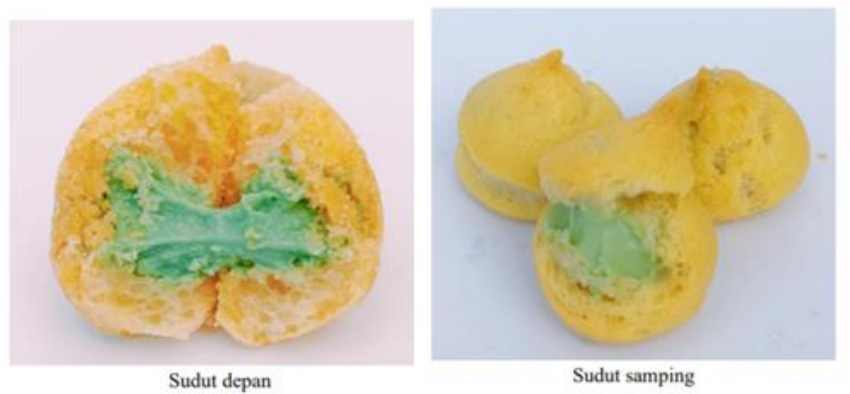

Gambar 3. Hasil Foto Produk Makanan
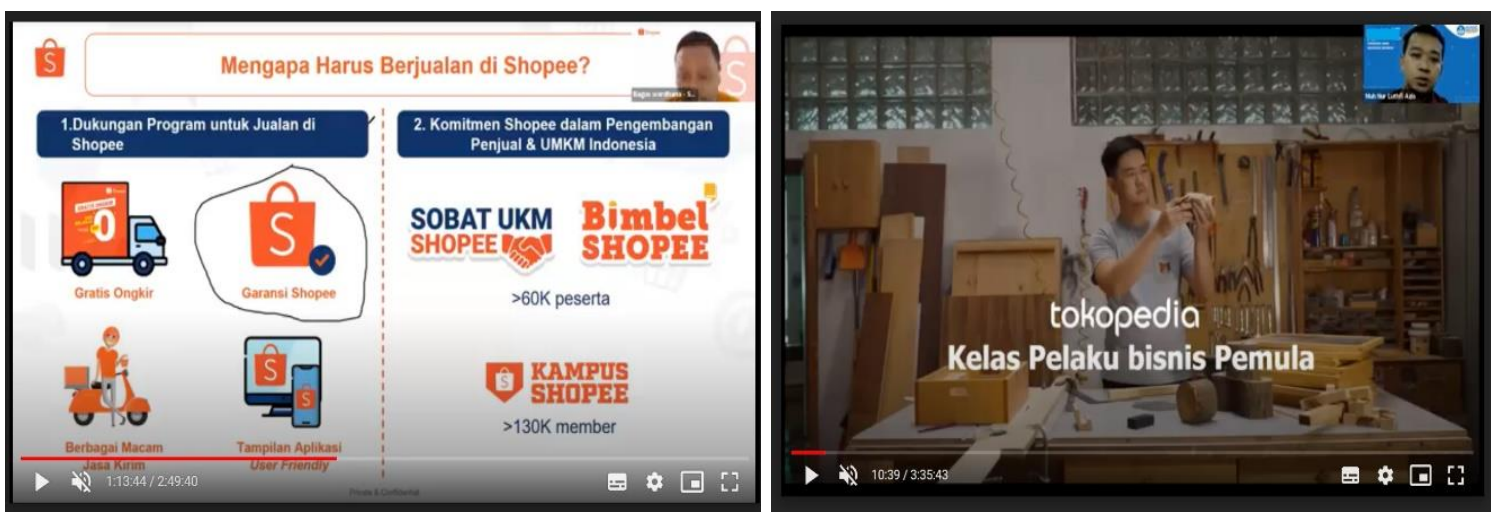

Gambar 4. Penyampaian Materi Pembuatan Toko Shopee dan Tokopedia

\section{Temuan Kendala Pelaksanaan}

Ada beberapa kendala yang ditemukan dalam pelaksanaan pengabdian kepada masyarakat dengan tema digital marketing, diantaranya:

a. Kendala dari peserta

1) Beragamnya peserta yang berasal dari latar belakang pendidikan yang berbeda, menjadikan peserta sangat heterogen dengan berbagai kemampuan yang dimiliki peserta

2) Peserta sering mengalami masalah jaringan, sehingga ada beberapa peserta yang kurang optimal dalam mengikuti kegiatan ini

3) Jaringan internet yang tidak stabil dari peserta menjadikan peserta tidak bisa menghidupkan video pada saat meet berlangsung, sehingga hanya nama peserta yang muncul

b. Kendala dari pemateri

1) Pada saat menyampaikan materi pembelajaran praktek atau tutorial, pengajar sering mengalami kesulitan karena tidak bisa memantau progres dari masingmasing peserta 
2) Keaktifan dalam setiap kelas sering didominasi oleh 3-5 peserta, sehingga pengajar harus berusaha lebih inovatif dalam proses pembelajaran.

3) Pemateri kesulitan dalam melakukan diskusi yang disebabkan oleh adanya jaringan internat yang tidak stabil dari peserta pelatihan, sehingga hasil diskusi kurang berjalan dengan baik.

\section{Solusi yang Dijalankan}

Solusi yang ditawarkan atau dijalankan tim pelaksana untuk pelaksanaan pengabdian kepada masyarakat dengan tema digital marketing, diantaranya:

a. Peserta yang tidak bisa mengikuti kegiatan pembelajaran secara online dapat melihat hasil rekaman pelatihan yang telah dilakukan.

b. Untuk meningkatkan pemahaman dan pengetahuan peserta pelatihan, maka dibuat group WA untuk memberikan arahan, diskusi serta membimbing peserta dalam menjalankan usaha secara online.

c. Untuk meningkatkan kemampuan peserta pelatihan, maka panitia juga membuat e-book yang berkaitan dengan pelatihan digital marketing, dimana e-book ini diberikan secara gratis oleh peserta pelatihan untuk meningkatkan kinerja toko onlinenya.

\section{Dampak Kegiatan}

Kegiatan pengabdian kepada masyarakat dengan kelompok sasaran UMKM di Kabupaten Madiun, telah memberikan dampak pada perubahan perilaku pada mitra sasaran. Perubahan perilaku ini terlihat dari aktivitas peserta pelatihan yang awalnya belum memiliki toko online, maka setelah mengikuti pelatihan menjadi memiliki toko online.

\section{Simpulan dan Rekomendasi}

Pelaksanaan pengabdian kepada masyarakat dengan tema digital marketing dengan peserta sebanyak 16 orang, dimana peserta adalah pelaku usaha yang telah memiliki usaha dengan skala mikro dan menengah. Dalam pelaksanaan pengabdian kepada masyarakat ini, peserta diajarkan dan dibimbing untuk memiliki toko online di marketplace Shopee dan Tokopedia, dengan harapan pelaku usaha dapat naik tingkat dalam menjalankan usahanya. Untuk pelaksanaan kegiatan ini telah berjalan dengan lancar dan kehadiran peserta dalam setiap pertemuan mencapai 90\%. Selain itu, peserta juga dapat mempelajari materi secara offline maupun online dari hasil rekaman yang telah dibuat.

Untuk memberikan hasil yang optimal terhadap kegiatan digital marketing ini, maka ada beberapa rekomendasi atau tindak lanjut yang perlu dilakukan, diantaranya: peserta yang telah selesai mengikuti pengabdian kepada masyarakat dengan tema digital marketing, diharapkan terus menjalankan usaha toko online yang telah dibuat selama mengikuti kegiatan pelatihan digital marketing. Untuk program abdimas selanjutnya, perlu melibatkan pelaku usaha toko online yang telah sukses untuk berbagi ilmu dan pengalaman serta memberikan kesempatan untuk mengajar dalam jumlah jam yang ideal. Pelaksanaan pelatihan dilakukan dalam kelas kecil, sehingga mudah dalam melakukan kontrol dari hasil pembelajaran pelatihan. 


\section{Penghargaan}

Kegiatan pengabdian kepada masyarakat dengan tema digital marketing tahun 2021 telah selesai dijalankan dan kmi mengucapkan terima kasih pada Lembaga Penelitian dan Pengabdian Kepada masyarakat Universitas PGRI Madiun yang telah banyak memberikan dukungan dalam pelaksanana kegiatan ini. Terimakasih kepada tim dosen Teknik Informatika dan peserta pelatihan yang telah konsisten dalam kegiatan ini.

Kami menyadari bahwa pelaksanaan pengabdian kepada masyarakat dengan tema digital marketing ini masih jauh dari kata sempurna. Oleh karena itu, kami selalu siap untuk menerima masukan agar kegiatan selanjutnya dapat berjalan dengan baik.

\section{Daftar Pustaka}

Djamaludin, D., Aviasti, A., \& Rukmana, O. (2016). Peningkatan Kemampuan Usaha Kecil Menengah Di Wilayah Bandung Raya Dalam Pemanfaaatan Internet Sebagai Sarana Pemasaran Dan Perluasan Jangkauan Pasar. ETHOS (Jurnal Penelitian Dan Pengabdian), 5, 125. https://doi.org/10.29313/ethos.v0i0.1682

Febriyantoro, M. T., \& Arisandi, D. (2018). Pemanfaatan Digital marketing Bagi Usaha Mikro, Kecil Dan Menengah Pada Era Masyarakat Ekonomi Asean. JMD: Jurnal Riset Manajemen \& Bisnis Dewantara, 1(2), 61-76. https://doi.org/10.26533/jmd.v1i2.175

Gumilang, R. R. (2019). Implementasi Digital marketing Terhadap Peningkatan Penjualan Hasil Home Industri. 10(1), 9-14.

Gunawan, A. (2020). Pelatihan Digital entrepreneurship untuk Mewujudkan Generasi Milenial Berjiwa Wirausaha. Abdimas Dewantara, 3(1), 38-45. https://doi.org/10.30738/ad.v3i1.4311

Hapsoro, B. B. (2019). Peran Digital marketing sebagai Upaya Peningkatan Omset Penjualan Bagi Klaster UMKM di Kota Semarang. Jurnal Abdimas, 23(2), 117-120.

Harto, B., Rozak, A., \& Rukmana, A. Y. (2021). Strategi Marketing Belah Doeren Melalui Digital marketing Terhadap Keputusan Pembelian Dimediasi Brand Image. 7(1), 67-74.

Irfani, H., Yeni, F., \& Wahyuni, R. (2020). Pemanfaatan Digital marketing Sebagai Strategi Pemasaran Pada Ukm Dalam Menghadapi Era Industri 4.0. JCES (Journal of Character Education Society), 3(3), 651-659.

Nugraha, A. E. P. (2017). Jurnal NUSAMBA Vol2 No.1 2017. Jurnal Nusamba, 2(1), 1-9. https://ojs.unpkediri.ac.id/index.php/manajemen/article/view/701

Oktaviani, F., \& Rustandi, D. (2018). Implementasi Digital marketing dalam Membangun Brand Awareness. PRofesi Humas: Jurnal Ilmiah Ilmu Hubungan Masyarakat, 3(1), 1. https:// doi.org/10.24198/prh.v3i1.15878

Perwita, D. (2021). Telaah digital entrepreneurship: suatu implikasi dalam mengatasi permasalahan ekonomi. Jurnal Promosi, 9(2), 40-51. 